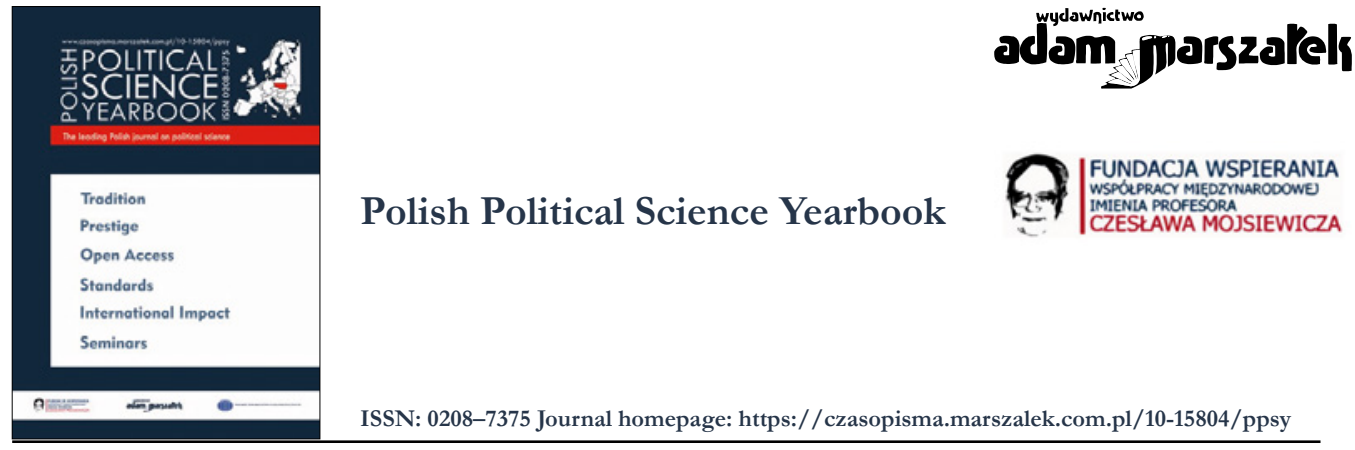

\title{
Book Review: Joanna Marszałek-Kawa, Maria Ochwat (Eds.), Problems, Threats and Challenges for Peace and Conflict Resolution, Toruń 2021, pp. 256.
}

\section{Agnieszka Lipska-Sondecka \\ ORCID: 0000-0001-8911-4087}

To cite this article please include the following information:

- Journal title: Polish Political Science Yearbook

- Volume number: 50

- Year of publication: 2021

- Published ahead-of-print

Example styles:

[APA Style]: Lipska-Sondecka, A. (2021). Book Review: Joanna Marszałek-Kawa, Maria Ochwat (Eds.), Problems, Threats and Challenges for Peace and Conflict Resolution, Toruń 2021, pp. 256. Polish Political Science Yearbook, 50(4), pages. DOI: https://doi.org/10.15804/ppsy202159

[Chicago Style]: Agnieszka Lipska-Sondecka, "Book Review: Joanna Marszałek-Kawa, Maria Ochwat (Eds.), Problems, Threats and Challenges for Peace and Conflict Resolution, Torun 2021, pp. 256" Polish Political Science Yearbook 50, no. [4] (2021).

To link to this article: https://doi.org/10.15804/ppsy202159

Published ahead-of-print

曲 Final submission: 17 November 2021

Published online: 17 December 2021

Printed issue: 2021

Submit your article to PPSY 


\author{
Agnieszka Lipska-Sondecka \\ University of Szczecin (Poland) \\ ORCID: 0000-0001-8911-4087 \\ e-mail: agnieszka.lipska-sondecka@usz.edu.pl
}

\title{
Book Review: Joanna Marszałek-Kawa, Maria Ochwat (Eds.), Problems, Threats and Challenges for Peace and Conflict Resolution, Torun 2021, pp. 256.
}

The presented book proposes an interesting view on peaceful resolving disputes and international conflicts. War and peace are two phenomena that have accompanied individuals, social groups, and huge human collectives since the birth of civilizations. The world without wars, human dramas, and unfortunates is a myth, utopia, beautiful but unattainable idea. As long as there is a man, there will be violence and conflicts in individual, interpersonal, local, regional, and finally global scales. In this context, studies on peace take a new meaning. The most important point of reflection becomes building a feeling of security as an elementary need of each human. Creating such a condition is a requirement of the development and progress of our civilization. Ensuring safety also is a condition for our survival, while the state (perceived in the categories of a social organization of universal character) takes responsibility for its realization.

Understanding the essence of security by broad social circles is one of the most important issues concerning the culture-forming function of science. From that perspective, the reviewed book perfectly inscribes into not yet fully developed academic way, which main problems oscillate around the broad spectrum of issues related to building individuals', groups', and nations' wealth in all aspects of our functioning.

Eliminating threats and building a safe haven for civilizational and cultural development depends, first and foremost, on deriving from past experiences. All that we know today can be placed on the time axis. Building our world, we make it for the future, even though we are doing that here and now. Building a world in which we minimize the risk of wars, conflicts, and disputes is particularly important in relation to security. Based on past experiences and knowledge about previous mistakes, we can create norms and institutions that will help us ensure safe being in the future. The task of researchers is to deliver knowledge, which should answer the question of how to act efficiently to live safer and wealthier? 
Issues concerning peaceful resolving disputes and conflicts meet criteria for becoming an area of deepen reflections, analyses, and opinions of scholars representing various disciplines of science: political scientists, social scientists, legal scientists, philosophers, cultural scientists, anthropologists, and all those for whom freedom from various kinds of threats is a shared value around which the activities of all participants of social life integrate. Such an interdisciplinary approach to the subject matter is presented in the book Problems, Threats and Challenges for Peace and Conflict Resolution edited by Joanna Marszałek-Kawa and Maria Ochwat.

The book consists of eight studies devoted to peaceful resolving disputes and conflicts in the contemporary world. The authors of chapters represent various scientific disciplines and units. They share with the readers their knowledge, experience, and familiarity with conflict-generating mechanisms and impact on social and political relations. In Phill Gittins' (and co-authors) paper, we can see differentiated perspectives on war and peace. The authors from five continents focus on the main opportunities and obstacles in building peace and share their reflections on building an international area free from war and conflicts. Anna Adamus-Matuszyńska, in the paper about the concepts of solving disputes and conflicts, indicates that "conflict resolution" has become a social science phenomenon, which serves researchers for describing and analyzing difficult and complex disputable situations. In a sense, we can find the continuation of these reflections in Monika A. Fennell's paper, in which the author shows innovative tools used in the area of justice in terms of conflict resolution on the example of the United States. Helen Tanner studies a potential attitude of forgiveness and its role in building new social relations. She indicates and even encourages us to adopt such an attitude as a personal practice that enables changing the world for the better. Another paper focuses on the role of education in building sustainable relations based on mutual respect and understanding differences between us. The author, Sudarat Tuntivivat, also shows its political implications for shaping social relations built on the fundamental principles resulting from respecting human rights. Another author - Vanessa Tinker - follows a similar trail. Based on the example of a conflict between Turkey and Kurds living on its territory, she indicates that education of equality among diversity can become a turning point in building attitudes of peaceful resolving of this complicated situation. Kishu Daswani analyzes legal provisions in terms of citizenship and, based on the example of India, demonstrates legal, political, social, and religious results of authorities' activities that may lead to new tensions, crises, and conflicts. The book finishes with the chapter written by Dickson Ogbonnaya Igwe about the necessity of finishing demilitarization in Sub-Saharan Africa. According to the author, only finishing these actions may bring long-waited peace and security.

It is worth underlining that the reviewed book's cognitive value is also visible in a skillful connection of practical (expert) knowledge with academic reflections. The chapters' authors are not only recognized practitioners but also academic lecturers. The proper correlating these layers has a great meaning for evaluating the reviewed volume. There are not many 
elaborations and analyses, which skillfully select and merge the theoretical and practical sides of the subject matter.

Finally, the volume's editors also deserve the words of recognition since they had undertaken a. difficult task of creating a set of works that will discuss complex and still superficially analyzed problems. They accomplished that task, so the book is worth recommending to all those for whom peace and security are elementary values building the well-being of all humans, social groups, and nations. I encourage you to read it. It is worth your time. 